\title{
Acanthosis nigricans in type 2 diabetes: prevalence, correlates and potential as a simple clinical screening tool - a cross-sectional study in the Caribbean
}

Sarasvati Bahadursingh*, Catherine Mungalsingh, Terence Seemungal and Surujpal Teelucksingh

\begin{abstract}
Background: This study aimed to evaluate the role of acanthosis nigricans (AN) as a marker of Type 2 Diabetes Mellitus (T2DM) by studying its prevalence and relationship with age, ethnicity, anthropometry and other risk factors for T2DM in the Trinidadian population.
\end{abstract}

Methods: 311 successive adult patients with T2DM were recruited at diabetic clinics and inpatient wards across Trinidad. The presence, severity and texture of AN at the neck were assessed. Demographic, clinical and anthropometric characteristics were also measured, and logistic regression was used to model their relationship with presence of AN.

Results: The mean (SD) age was 58.1 years (12.6). 55.6\% were female. 61.1\% were East Indian, 24.4\% African and $14.5 \%$ mixed ethnicity. The mean (SD) BMI was $27.3 \mathrm{~kg} / \mathrm{m}^{2}$ (6.0) and the mean (SD) waist circumference was $96.7 \mathrm{~cm}$ (14.2). Prevalence of AN was $52.7 \%$ (95\% Cl 47.2, 58.3).

There was a greater odds of AN among diabetic patients who were: younger $(p<0.001)$; female $(\mathrm{OR} 1.67 ; 95 \% \mathrm{Cl}$ $1.06,2.62)$; or East Indian rather than African $(0.45 ; 0.26,0.77)$ or mixed $(0.43 ; 0.22,0.84)$ descendents. There was a greater age-, sex- and ethnicity-adjusted odds of AN among those: overweight $(3.98 ; 2.10,7.55)$ or obese $(8.31 ; 3.84$, 18.00) versus normal BMl; centrally obese $(4.72 ; 2.65,8.43)$; with history of hypertension $(2.19 ; 1.27,3.79)$ or history of hypercholesterolemia $(1.72 ; 1.02,2.90)$, but there was no evidence of this demographic-adjusted association $(p>0.4)$ between AN and history of previous Ml or CVA, family history of T2DM, T2DM treatment regimen, duration of T2DM or random blood glucose.

On further multivariable analysis, only age, sex, ethnicity, BMI and waist circumference were independently associated with AN $(p<0.05)$ and the effect of BMl varied with ethnicity.

Conclusions: There was a high prevalence of AN both overall and across age, sex and ethnic groups of diabetic patients. AN exhibited much potential as a valuable addition to T2DM risk assessment in the Trinidadian and similar settings.

Keywords: Acanthosis nigricans, Type 2 diabetes mellitus, Prevalence, Obesity, Screening, Risk factor, Age, Sex, Ethnicity, BMI, Waist circumference

\footnotetext{
*Correspondence: sarasvati_b@hotmail.com

Department of Clinical Medical Sciences, The University of the West Indies,

St. Augustine, Trinidad and Tobago W.I
}

\section{() Biomed Central}

(c) 2014 Bahadursingh et al.; licensee BioMed Central Ltd. This is an Open Access article distributed under the terms of the Creative Commons Attribution License (http://creativecommons.org/licenses/by/4.0), which permits unrestricted use, distribution, and reproduction in any medium, provided the original work is properly credited. The Creative Commons Public Domain Dedication waiver (http://creativecommons.org/publicdomain/zero/1.0/) applies to the data made available in this article, unless otherwise stated. 


\section{Background}

Trinidad and Tobago is a twin-island unitary republican state in the Southern Caribbean with a population of 1.3 million inhabitants derived mostly of descendants from peoples of India (35\%) and West Africa (34\%) with a sprinkling of others of Chinese, Syrian/Lebanese and Caucasoid stock. Arising out of this background is an expanding group of mixed ethnicity who currently accounts for approximately $23 \%$ of the population [1].

As early as the 1960's, a national survey of more than 20,000 individuals revealed an adult prevalence of Type 2 diabetes mellitus (T2DM) of $3.5 \%$, already one of the highest in the Hemisphere, and identified a higher prevalence among Indian descendants [2]. Twenty years later, the St James Survey, a longitudinal study in an urban setting, confirmed this persistently increased risk for diabetes among East Indians, about twice that for Africans. Interestingly people of mixed ancestry were identified in that study to exhibit low risk for both diabetes and its associated complication, ischaemic heart disease [3].

More recently data from the Trinidad and Tobago Chronic Non-Communicable Disease Risk Factor (Pan American STEPS) Survey showed a prevalence of T2DM of $20 \%$ among individuals between 15-64 years of age [4]. Against this background, it is therefore not surprising that T2DM and its complications account for considerable use of resources, bed space and clinical load [5].

Given this burden of disease, clinicians require sensitive, safe and inexpensive screening tests so that interventions can be instituted earlier. In some populations, acanthosis nigricans (AN) has been recommended as a suitable tool for such screening [6], as its association with T2DM, insulin resistance and obesity is wellestablished $[7,8]$. However, studies have reported that the prevalence of AN varies greatly in different ethnic groups [9] and any recommendation for its use must be relevant to the population for which this is intended. Thus Grandhe et al. report that up to two-thirds of type 2 diabetic patients from North India will display this sign [10] whereas a study from Nigeria showed that less than $20 \%$ will so do [11]. In general, darker races are more likely to exhibit this sign than are Whites [9].

This study aimed to evaluate the role of $\mathrm{AN}$ as a marker of T2DM by studying its prevalence and relationship with age, ethnicity, anthropometry and other risk factors for T2DM in the Trinidadian population.

\section{Methods}

This is a cross-sectional study. Three hundred and eleven (311) successive subjects were recruited at dedicated diabetic outpatient clinics and the general medical and surgical inpatient wards at the Port of Spain General Hospital, San Fernando General Hospital and Eric Williams Medical Sciences Complex in Trinidad. These hospitals are the three main public hospitals and together serve a national population of 1.3 million. Approval was obtained from the ethics committees of participating hospitals and of the University of the West Indies, and research was in compliance with the Helsinki Declaration.

Included in this study were individuals 18 years of age and older with T2DM (according to the World Health Organisation (WHO) definition [12]) and who were able to give informed consent. Patients were excluded if they had other endocrine or systemic diseases known to result in AN. More specifically, patients with a history of, being investigated for, or diagnosed with one or more of the following were excluded: internal malignancy (gastrointestinal); autoimmune conditions such as systemic lupus erythematosus, scleroderma, Sjogren's syndrome and Hashimoto's thyroiditis. Also excluded from the study were subjects with a history of intake of drugs which can cause AN (nicotinic acid, oral contraceptives, topical fusidic acid, methyltestosterone and triazinate) $[8,9]$ as well as subjects who were unable to give a cohesive history, had a high alcohol intake ( $>14$ units/week for women and $>21$ units/week for men), used illicit drugs, were less than 18 years of age or who did not have T2DM.

The main outcome measure was AN. Subjects were examined for the presence of AN at the neck, and its severity and texture were graded using standard scales as described by Burke et al. [13]. Severity was graded from 0 to 4 as follows: grade 0 - not visible on close inspection; grade 1 - clearly present on close visual inspection; grade 2 - limited to base of the skull but does not extend to the lateral margins of the neck; grade 3 - extending to the lateral margins of the neck but not visible from the front; and grade 4: extending to the anterior neck. The texture of $\mathrm{AN}$ at the neck was graded from 0 to 3 as follows: Grade 0 - smooth to touch, no differentiation from normal skin to palpation; Grade 1- rough to touch, clearly differentiated from normal skin; Grade 2 - coarseness can be observed visually, portions of the skin clearly raised above other areas; and Grade 3 - extremely coarse, "hills and valleys" observable on visual examination. The presence of AN at other typical sites, including knuckles, elbows, axillae and knees, was also documented. Those patients with localized hyperpigmentation without skin thickening were not considered to have AN [13]. AN was assessed by a single trained observer.

Demographic and clinical characteristics, including anthropometric measurements, were also taken. An administered questionnaire was used to collect data on: age; sex; self-reported ethnicity; previous history of hypercholesterolemia, hypertension, myocardial infarction (MI) and/or cerebrovascular accident (CVA); family history of T2DM; duration of T2DM; and treatment with oral hypoglycaemics, insulin or both. The absence of the exclusion criteria mentioned previously was also ascertained. 
The most recent random blood glucose (RBG) level was obtained from medical records as a surrogate for blood glucose control in the absence of consistently available HbA1c. Anthropometric measurements taken included the weight and height of all subjects. These were measured according to usual clinical practice, and body mass index (BMI) was calculated as weight in kilograms divided by height in metres squared. Waist circumference was measured midway between the lower margin of the ribcage and the superior rim of the ilium using a flexible tape measure.

\section{Statistical analysis}

Data were analysed using Stata Version 13.0. All statistical tests were interpreted at the $5 \%$ level of significance. Population characteristics were summarised. The distribution of AN both overall and by each population characteristic was examined. The effect of each explanatory variable on the odds of AN was summarised using odds ratios (ORs) with 95\% confidence intervals (CIs) that were adjusted for the confounding effect of demographic characteristics of age, sex and ethnicity in a logistic regression model. The likelihood ratio test (LRT) was used to test the age-, sex- and ethnicity-adjusted association between $\mathrm{AN}$ and each explanatory variable. Age, BMI and waist circumference were categorised using clinically relevant cut-points for data summary, measures of effect and hypothesis testing. Age was adjusted for in continuous form.

Multivariable logistic regression modelling was used to further explore confounding by other explanatory variables. All measured variables were included in the initial model and backward elimination of terms was performed: terms with the largest $\mathrm{p}$ values on the Wald test were eliminated stepwise until all terms had $\mathrm{p}<0.05$. Subsequently, interactions of all retained terms with age, sex and ethnicity were investigated and retained if $\mathrm{p}<0.05$. All continuous variables were modelled in original form. This final model determined was later refitted with BMI in categorical form to further explore and interpret the interaction detected.

Characteristics found to be independently associated with the presence AN were further evaluated for a simple linear trend with increasing severity of AN - for descriptive interest. The chi-squared test for trend was used to evaluate evidence of a trend in the proportion of participants with a binary characteristic across increasing grades of AN severity; each ethnic group was treated as a binary characteristic. The ANOVA trend test was used to assess linear trends in the mean of continuous variables across increasing severity of AN. Regression coefficients were subsequently evaluated and tested in linear and logistic regression models for continuous and categorical variables respectively. The Cuzick [14] nonparametric extension of the Wilcoxon rank-sum test [14] was used to test for a trend in the average texture of AN across increasing grade of AN severity.

An estimated sample size of 272 participants was required to estimate the prevalence of $\mathrm{AN}$ among patients with T2DM with a total confidence interval width of 0.10 , confidence level of $90 \%$, and an expected proportion of $\mathrm{AN}$ of 0.50 . The estimated prevalence of $\mathrm{AN}$ in T2DM varied widely in the literature from $36 \%$ in one study of a diverse ethnic population [15] to $63 \%$ in a population of North Indians [10]. An expected proportion of AN of 0.5 therefore chosen since it corresponded to the largest estimated sample size.

\section{Results}

\section{Sample characteristics}

The study sample comprised 311 patients with T2DM. Their demographic and clinical characteristics are summarised in Table 1 . Their mean age was 58.1 years (SD 12.6; range 25-99 years). 55.6\% were female. $61.1 \%$ were East Indian, $24.4 \%$ African and $14.5 \%$ mixed ethnicity. The mean BMI was $27.3 \mathrm{~kg} / \mathrm{m}^{2}$ (SD 6.0) and the mean waist circumference was $96.7 \mathrm{~cm}$ (SD 14.2).

\section{Prevalence of AN}

The prevalence of AN among all study participants was $52.7 \%$ (95\% CI 47.2, 58.3). Table 1 shows the estimated prevalence of AN in different subgroups. Of note, $58.4 \%$ of females compared to $45.7 \%$ of males had AN. The prevalence of AN decreased from $75.0 \%$ in the youngest age group (25-39 years) to $33.9 \%$ in the oldest age group ( $\geq 70$ years). $60.5 \%$ of participants of East Indian descent had AN as compared to $40.8 \%$ and $40.0 \%$ of participants of Africans and mixed descent respectively. The prevalence of AN among normal-BMI participants was $30.2 \%$ as compared to $61.7 \%$ and $76.8 \%$ among overweight and obese participants respectively and $68.3 \%$ of those with central obesity had AN compared to $36.5 \%$ of those without.

\section{Age-, sex- and ethnicity-adjusted associations with AN}

Table 1 further compares the prevalence (via odds ratios) of $\mathrm{AN}$ in different demographic and clinical subgroups. There was a greater odds of AN among those who were: younger ( $\mathrm{p}<0.001$ ); female (OR 1.67; 95\% CI 1.06, 2.62) and of East Indian descent rather than of African (OR 0.45; 95\% CI 0.26, 0.77) or mixed (OR 0.43; 95\% CI 0.22, 0.84 ) descent. After adjusting for the confounding effect of demographic features, there was a greater age- sexand ethnicity-adjusted odds of AN among those who were: overweight (OR 3.98; 95\% CI 2.10, 7.55) or obese (OR 8.31; 95\% CI 3.84, 18.00) compared to participants of normal BMI; had central obesity (OR 4.72; 95\% CI $2.65,8.43$ ); had a history of hypertension (OR 2.19; $95 \%$ CI 1.27, 3.79) or a history of hypercholesterolemia (OR 1.72; 95\% CI 1.02, 2.90). 
Table 1 Acanthosis Nigricans (AN): prevalence, and age-, sex- and ethnicity-adjusted associations with demographic and clinical characteristics

\begin{tabular}{|c|c|c|c|c|c|c|c|c|}
\hline \multirow{3}{*}{$\begin{array}{l}\text { Characteristic } \\
\text { Age }(\text { years) }\end{array}$} & \multirow{3}{*}{$\begin{array}{l}\text { Subgroup } \\
25-39\end{array}$} & \multicolumn{2}{|c|}{$\begin{array}{l}\text { Overall frequency of } \\
\text { characteristic }\end{array}$} & \multicolumn{2}{|c|}{$\begin{array}{c}\text { Prevalence of AN in } \\
\text { subgroup }\end{array}$} & \multirow{2}{*}{\multicolumn{2}{|c|}{$\begin{array}{c}\text { Age }^{*}-\text {, sex- \& ethnicity-adjusted } \\
\text { OR }(95 \% \mathrm{CI})^{\dagger}\end{array}$}} & \multirow{3}{*}{ p value ${ }^{\ddagger}$} \\
\hline & & \multirow{2}{*}{$\begin{array}{c}\mathbf{N} \\
28\end{array}$} & \multirow{2}{*}{$\begin{array}{l}\text { (\%) } \\
(9.0)\end{array}$} & \multirow{2}{*}{$\begin{array}{l}\mathbf{N} \\
21\end{array}$} & \multirow{2}{*}{$\begin{array}{c}\text { (\%) } \\
(75.0)\end{array}$} & & & \\
\hline & & & & & & 5.84 & $(2.11,16.18)$ & \\
\hline & $40-49$ & 42 & $(13.5)$ & 30 & (71.4) & 4.87 & $(2.04,11.60)$ & \\
\hline & $50-59$ & 94 & $(30.2)$ & 56 & (59.6) & 2.87 & $(1.44,5.72)$ & \\
\hline & $60-69$ & 91 & $(29.3)$ & 38 & $(41.8)$ & 1.40 & $(0.70,2.79)$ & \\
\hline & $\geq 70$ & 56 & $(18.0)$ & 19 & (33.9) & 1 & & $<0.001$ \\
\hline & All [mean(SD)] & {$[58.1$} & $(12.6)]$ & & & & & \\
\hline \multirow[t]{2}{*}{$\operatorname{Sex}^{+}$} & Males & 138 & $(44.4)$ & 63 & $(45.7)$ & 1 & & \\
\hline & Females & 173 & $(55.6)$ & 101 & $(58.4)$ & 1.67 & $(1.06,2.62)$ & 0.026 \\
\hline \multirow[t]{3}{*}{ Ethnicity $^{\dagger}$} & East Indian & 190 & $(61.1)$ & 115 & $(60.5)$ & 1 & & \\
\hline & African & 76 & $(24.4)$ & 31 & $(40.8)$ & 0.45 & $(0.26,0.77)$ & \\
\hline & Mixed & 45 & $(14.5)$ & 18 & $(40.0)$ & 0.43 & $(0.22,0.84)$ & 0.003 \\
\hline Body Mass Index & Underweight & 6 & $(2.2)$ & 0 & $(0.0)$ & & & \\
\hline \multirow[t]{4}{*}{$\left(\mathrm{kg} / \mathrm{m}^{2}\right)^{\xi_{1}}$} & Normal & 106 & $(38.5)$ & 32 & $(30.2)$ & 1 & & \\
\hline & Overweight & 94 & $(34.2)$ & 58 & $(61.7)$ & 3.98 & $(2.10,7.55)$ & \\
\hline & Obese & 69 & $(25.1)$ & 53 & (76.8) & 8.31 & $(3.84,18.00)$ & $<0.001$ \\
\hline & All [mean(SD)] & 27.3 & $(6.0)$ & & & & & \\
\hline Waist Circumference & Normal & 148 & $(50.5)$ & 54 & $(36.5)$ & & & \\
\hline \multirow[t]{2}{*}{$(\mathrm{cm})^{\S, * *}$} & Central obesity & 145 & $(49.5)$ & 99 & $(68.3)$ & 4.72 & $(2.65,8.43)$ & $<0.001$ \\
\hline & All [mean(SD)] & 96.7 & $(14.2)$ & & & & & \\
\hline \multirow[t]{2}{*}{ Hypertension } & No & 104 & $(33.4)$ & 49 & $(47.1)$ & 1 & & \\
\hline & Yes & 207 & $(66.6)$ & 115 & $(55.6)$ & 2.19 & $(1.27,3.79)$ & 0.004 \\
\hline \multirow[t]{2}{*}{ Hypercholesterolemia } & No & 121 & $(38.9)$ & 56 & $(46.3)$ & 1 & & \\
\hline & Yes & 190 & $(61.1)$ & 108 & $(56.8)$ & 1.72 & $(1.02,2.90)$ & 0.040 \\
\hline \multirow[t]{2}{*}{ Family history of $\mathrm{T}^{2} \mathrm{DM}^{\S}$} & No & 54 & $(17.4)$ & 22 & $(40.7)$ & 1 & & \\
\hline & Yes & 256 & $(82.6)$ & 141 & $(55.1)$ & 1.3 & $(0.68,2.48)$ & 0.420 \\
\hline \multirow[t]{2}{*}{ CVA or Ml } & No & 233 & $(74.9)$ & 122 & $(52.4)$ & 1 & & \\
\hline & Yes & 78 & $(25.1)$ & 42 & $(53.8)$ & 1.26 & $(0.72,2.22)$ & 0.413 \\
\hline \multirow[t]{3}{*}{ Diabetes Treatment } & Oral & 192 & $(61.7)$ & 101 & $(52.6)$ & & & \\
\hline & Oral \& Insulin & 28 & $(9.0)$ & 11 & (39.3) & 0.63 & $(0.26,1.54)$ & \\
\hline & Insulin & 91 & $(29.3)$ & 52 & $(57.1)$ & 1.14 & $(0.67,1.96)$ & 0.467 \\
\hline $\mathrm{RBG}(\mathrm{mg} / \mathrm{dL})^{\S}$ & All $[\operatorname{med}(I Q R)]$ & {$[145$} & $(84)]$ & & & 1.00 & $(0.998,1.004)$ & 0.584 \\
\hline Duration of T2DM (yrs) $)^{\S}$ & All $[\operatorname{med}(I Q R)]$ & {$[10$} & $(16)]$ & & & 1.00 & $(0.98,1.03)$ & 0.847 \\
\hline Overall & & 311 & (100) & 164 & $(52.7)$ & & & \\
\hline
\end{tabular}

Abbreviations: AN Acanthosis Nigricans, OR Odds Ratio, Cl Confidence Interval, SD Standard Deviation, BMI Body Mass Index, T2DM Type 2 Diabetes Mellitus, CVA Cerebrovascular accident, MI Myocardial Infarction, RBG Random Blood Glucose, med median, IQR Inter-quartile range. *age adjusted for as a continuous variable; ${ }^{\dagger}$ Odds Ratios for variables age, sex and ethnicity are univariable analyses; ${ }^{\ddagger} p$ value for age-, sex- and ethnicity-adjusted association with AN from likelihood ratio test; $^{\S} 36,18,1,14,1$ missing observations for BMl, waist circumference, family history of T2DM, RBS and duration of T2DM respectively. No missing observations for other variables. " BMI $\left(\mathrm{kg} / \mathrm{m}^{2}\right)$ : Underweight: $<18.50$; Normal: 18.50-24.99; Overweight: 25.00-29.99; Obese $\geq 30.00$ [16]. ${ }^{* *}$ Central Obesity: waist circumference >102 cm in men and $>88 \mathrm{~cm}$ in women [17].

There was no evidence $(\mathrm{p}>0.40)$ of an age-, sex- and ethnicity- adjusted association between $\mathrm{AN}$ and a history of previous MI or CVA, a family history of T2DM, T2DM treatment regimen, the duration of T2DM or the RBG (Table 1).

\section{Multivariable analysis}

Backward elimination of variables was performed, and apart from the demographic characteristics of age, sex and ethnicity, only BMI and waist circumference remained significantly associated with $\mathrm{AN}(\mathrm{p}<0.05)$. 
A history of hypercholesterolemia or hypertension were no longer associated with AN after also adjusting for the effect of anthropometry. Remaining characteristics, which were not found to be associated with AN in previous analysis, remained that way and were eliminated from the model. Further investigation for interactions showed that the effect of BMI varied by ethnicity. There was no evidence of an interaction $(p>0.05)$ of any of the other variables in the model with either age, sex or ethnicity.

This final multivariable model is shown in Table 2 . Holding other variables in the model constant, females had a 2.33 greater odds of AN than males (95\% CI 1.27 4.27). A 10 year decrease in age and $10 \mathrm{~cm}$ increase in waist circumference was associated with a 1.87 (95\% CI $1.41-2.48)$ and 1.40 (95\% CI 0.99 - 1.99) greater odds of AN respectively. Among East Indians, overweight and obese diabetic patients had a 5.51 (95\% CI 2.34 - 12.98) and 12.27 (95\% CI 2.79 - 53.97) greater adjusted odds of AN respectively. However, among Africans and mixed participants, there was insufficient evidence of an association between BMI and AN. Among obese diabetic patients, East Indians had a greater odds of AN than those of African (OR 0.08; 95\% CI 0.01 - 0.45) or mixed (OR 0.14; 95\% CI 0.02 - 0.79) descent. In contrast, among normal-weight diabetic patients there was no evidence that the adjusted odds of AN in different ethnic groups was different; it was noted, however, that normal-weight Africans had a 1.7 times greater adjusted odds of AN than normal-weight East Indians, but there was insufficient evidence that this association was not due to chance $(\mathrm{p}=0.363)$.

\section{Severity and texture of AN}

The severity and texture of AN were graded separately. Table 3 summarises the proportion of participants with AN $(n=164)$ that fell into each of four categories of increasing severity of AN. In general, fewer diabetic patients had a more severe grade of AN: $39.6 \%$ were grade 1 compared to $11.6 \%$ who were graded as most severe (Grade 4). Participants with AN also fell into one of three grades of increasingly rougher texture. The texture of most AN was grade 1 (83.5\%), $12.2 \%$ were grade 2

Table 2 Demographic and clinical characteristics independently associated with presence of Acanthosis Nigricans (AN)

\begin{tabular}{|c|c|c|c|c|c|}
\hline Characteristic & & & $\mathrm{OR}^{*}$ & $\left(95 \% \mathrm{Cl}^{\dagger}\right)$ & p value ${ }^{\ddagger}$ \\
\hline Age (years) $^{\S}$ & & & 0.94 & $(0.91,0.97)$ & $<0.001$ \\
\hline \multirow[t]{2}{*}{$\operatorname{Sex}^{\S}$} & & Males & 1 & & \\
\hline & & Females & 2.33 & $(1.27,4.27)$ & 0.006 \\
\hline \multirow[t]{9}{*}{ Ethnicity" } & x Normal BM ${ }^{* *}$ & East Indian & 1 & & \\
\hline & & African & 1.70 & $(0.54,5.33)$ & 0.363 \\
\hline & & Mixed & 0.68 & $(0.18,2.53)$ & 0.570 \\
\hline & $x$ Overweight $^{* *}$ & East Indian & 1 & & \\
\hline & & African & 0.11 & $(0.03,0.41)$ & 0.001 \\
\hline & & Mixed & 0.44 & $(0.10,1.83)$ & 0.258 \\
\hline & $x$ Obese ${ }^{* *}$ & East Indian & 1 & & \\
\hline & & African & 0.08 & $(0.01,0.45)$ & 0.004 \\
\hline & & Mixed & 0.14 & $(0.02,0.79)$ & 0.027 \\
\hline \multirow[t]{9}{*}{ Body Mass Index (BMI) } & x East Indian & Normal BMI ${ }^{* *}$ & 1 & & \\
\hline & & Overweight $^{* *}$ & 5.51 & $(2.34,12.98)$ & $<0.001$ \\
\hline & & Obese $e^{* *}$ & 12.27 & $(2.79,53.97)$ & 0.001 \\
\hline & x African & Normal BMI* & 1 & & \\
\hline & & Overweight $^{* *}$ & 0.35 & $(0.08,1.64)$ & 0.183 \\
\hline & & Obese $e^{* *}$ & 0.59 & $(0.11,3.12)$ & 0.534 \\
\hline & x Mixed Ethnicity & Normal BMI* & 1 & & \\
\hline & & Overweight ${ }^{* *}$ & 3.51 & $(0.60,20.45)$ & 0.162 \\
\hline & & Obese $e^{* *}$ & 2.44 & $(0.37,16.06)$ & 0.352 \\
\hline Waist Circumference $(\mathrm{cm})^{\S}$ & & & 1.03 & $(1.00,1.07)$ & 0.060 \\
\hline
\end{tabular}

"OR: Odds Ratio of AN adjusted for other variables in the model including age, sex, ethnicity, BMI and waist circumference; ${ }^{\dagger} \mathrm{Cl}$ : Confidence Interval for adjusted $\mathrm{OR}^{\ddagger}{ }^{\mathrm{p}} \mathrm{p}$ value from Wald test. ${ }^{\S}$ Parameter estimates from final multivariable model "Parameter estimates from final model refitted with BMI as categorical, to illustrate the interaction between BMI and ethnicity. ${ }^{* * *}$ Body Mass Index (BMI) $\left(\mathrm{kg} / \mathrm{m}^{2}\right.$ ): Underweight: <18.50; Normal: 18.50-24.99; Overweight: 25.00-29.99; Obese $\geq 30.00$ [16] 
Table 3 Variation in the texture and presence of Acanthosis Nigricans (AN) at other sites by its severity

\begin{tabular}{|c|c|c|c|c|c|}
\hline \multirow[t]{2}{*}{ Severity of AN at the neck } & \multirow[b]{2}{*}{$\mathrm{N}$} & \multirow[b]{2}{*}{$(\%)$} & \multirow{2}{*}{$\begin{array}{c}\text { Texture of AN at the neck: } \\
\text { average grade (SD) }\end{array}$} & \multicolumn{2}{|c|}{ Proportion with AN at other sites ${ }^{*}$} \\
\hline & & & & $\mathbf{N}$ & (\%) \\
\hline Grade 0 (not present) & 146 & & - & 15 & $(10.3)$ \\
\hline Grade I & 65 & (39.6) & $1.00(0)$ & 35 & $(53.9)$ \\
\hline Grade II & 37 & $(22.6)$ & $1.11(0.31)$ & 25 & $(67.6)$ \\
\hline Grade III & 43 & $(26.2)$ & $1.28(0.45)$ & 28 & $(65.1)$ \\
\hline Grade IV & 19 & $(11.6)$ & $1.95(0.91)$ & 19 & $(100.0)$ \\
\hline Grades I - IV & 164 & $(100)$ & $1.21(0.50)$ & 122 & $(39.4)$ \\
\hline
\end{tabular}

"One missing value for the presence of AN at other sites of the body.

while only $4.3 \%$ fell into the highest category (Grade 3 ). Table 3 summarises the average texture of AN among participants with each grade of AN severity. More severe $\mathrm{AN}$ of the neck was associated with a rougher texture of AN of the neck $(\mathrm{p}<0.001)$.

\section{Linear trends by severity of AN}

Characteristics associated with the presence of AN were re-evaluated for a linear trend with increasing severity of AN. It was found that each grade increase in severity of AN was associated linearly with a 2.8 year decrease in age $(\mathrm{p}=0.001), 1.8 \mathrm{~kg} / \mathrm{m}^{2}$ increase in BMI $(\mathrm{p}<0.001)$, a $4.5 \mathrm{~cm}$ increase in waist circumference $(\mathrm{p}<0.001)$, a 1.46 times greater odds of being of East Indian descent (95\% CI 1.04, 2.06; p $=0.028)$ and a 0.65 times lower odds of being of African descent (95\% CI 0.43, 0.98; $\mathrm{p}=0.041$ ). For mixed participants, there was no evidence of a linear trend (OR 0.85; 95\% CI 0.53, 1.38; $\mathrm{p}=0.515)$ but the proportion of mixed participants did vary by $A N$ severity $(p=0.045)$. The proportion of: females, those with a history of hypertension and those with a history of hypercholesterolemia did not vary by severity of AN ( $>0.70)$ even though persons with these characteristics were overall more likely to have AN (as seen previously).

\section{AN at other sites of the body}

Among all study participants, 107 (34.5\%) had AN both at the neck and at other sites, 15 (4.8\%) had AN at other sites only, 57 (18.4\%) had AN at the neck only and the remaining 131 (42.3\%) did not have AN (one missing value for $\mathrm{AN}$ at other sites). Therefore, $\mathrm{AN}$ was documented at other sites of the body (axillae, elbows, knuckles and/or knees) in 122 (39.4\%) participants. Compared to those with $\mathrm{AN}$ at the neck, those without $\mathrm{AN}$ at the neck had a much lower odds (OR 0.06; 95\% CI 0.03, 0.11) of manifesting AN at other sites. As illustrated in Table 3, there was evidence that increasing severity of $\mathrm{AN}$ at the neck, was associated with an increasing proportion of diabetic patients with AN at other sites $(\mathrm{p}=0.001)$. Only 3 participants (1.0\%) had previously heard of AN.

\section{Discussion}

In Trinidad, screening for T2DM is opportunistic: in clinical settings, individuals are assessed for identifiable risk factors and those subjectively deemed high-risk are recommended for formal screening [18]. Currently, however, more than $50 \%$ of diabetic patients remain undiagnosed [18] and among those within reach of opportunistic screening, a major contributor to non-detection is the non-exhaustive collection of risk factors used to determine risk - it can exclude diabetic patients in whom traditional risk assessment is less convincing.

To address this issue, adjuncts to the current set of risk factors are needed but they must be carefully selected. New adjuncts should be not only sensitive, but should improve the sensitivity of the already-in-use pool of risk factors - they should broaden and strengthen the definition of a high-risk individual. Since timely risk assessment is vital in busy clinical settings, adjuncts must be efficiently and safely implementable. Lastly, a specific adjunct will limit the number of individuals wrongly classified as high-risk. Here, we will explore the potential of $\mathrm{AN}$ as an adjunct to T2DM risk assessment prior to formal T2DM screening in the Trinidadian population. We will explore the prevalence of AN among diabetic patients, the potential of AN to improve detection of T2DM and the innate qualities of the test that make it suitable.

AN is "a symmetric eruption characterized by hyperpigmented, velvety cutaneous thickening that can occur on any part of the body" [8]. It is considered a cutaneous marker of hyperinsulinemia and insulin resistance $[7,19]$ and has been established as a risk factor for T2DM $[6,20,21]$. AN has been formally recommended by the ADA as part of the T2DM risk assessment criteria for children and adolescents [22]. However, among adults, the implementation of AN in this capacity has been limited by infrequent manifestation in some populations [9].

In this Trinidad-based study, a relatively high manifestation of AN among diabetic patients was found - as many as 1 in 2 diabetic patients had AN. Of note, AN was $20 \%$ more likely to manifest in diabetic patients of 
East Indian than African or mixed origin - possibly due to a higher prevalence of ectopic fat and associated insulin resistance in the former [23]. However, the prevalence in all of these dominant ethnic groups was quite high: 2 in 5 diabetic patients of either African or mixed origin and 3 in 5 of East Indian origin demonstrated AN. This high prevalence of AN - both overall and among the major Trinidadian ethnic groups - strongly supports its implementation as a sensitive marker of T2DM in the unique ethnic population of Trinidad.

We also found the prevalence of AN to be high across age groups although we did observe a steady decrease in the prevalence of AN with increasing age. Formal recommendations of the American Diabetes Association (ADA) have recognised $\mathrm{AN}$ as a risk factor for T2DM in children and adolescents and have incorporated it into formal risk assessment protocols since 2000 [6]. Studies have found that approximately $60 \%$ to $92 \%$ of Black and Hispanic children with T2DM have AN [19] making it a highly sensitive marker in this age group. Indeed, in a recent survey among asymptomatic school-aged children screened for and confirmed with T2DM in Trinidad, all had AN [24]. The current study provides additional evidence of the value of $\mathrm{AN}$ as a valuable marker of T2DM risk in younger age groups. However, despite decreasing prevalence with age, more than one in three diabetic patients in this study over 70 years had AN: AN was still relatively prevalent in older age groups.

It is worth mentioning that this higher prevalence of $\mathrm{AN}$ in younger diabetic patients was partially explained by a higher prevalence of obesity in younger patients. However, even after adjusting for BMI and other factors, this trend of decreasing prevalence of AN with increasing age was still clearly observed. Litonjua et al. observed that newly diagnosed T2DM patients with AN "required markedly higher insulin doses to achieve euglycaemia" [15]. More severe insulin resistance in diabetic patients with AN may explain this decreasing prevalence of AN with age - a survivor effect.

The prevalence of AN was also high in both males (46\%) and females (58\%). Polycystic ovary syndrome (PCOS) is a well-established as an insulin-resistant state $[25,26]$ and may have accounted for some or all of the higher prevalence of AN among women with T2DM.

To be a valuable adjunct to the T2DM screening process, AN should improve risk assessment by traditional risk factors. As recommended by the ADA, "the decision to test for diabetes should ultimately be based on clinical judgment and patient preference" [22]. Thus as an established risk factor for T2DM that is highly prevalent among diabetic patients in the Trinidadian population, the observation of $\mathrm{AN}$ alongside other risk factor(s) for T2DM should increase clinical suspicion of T2DM. Additionally, the incidental or intentional observation of this well-established skin marker of insulin resistance should prompt further risk assessment for T2DM.

For example, in this study approximately $60 \%$ of diabetic patients were found to be obese or overweight, and of these patients, 70\% demonstrated AN. AN and obesity are associated with greater insulin resistance than obesity alone [27] and the finding of AN in an obese individual strengthens clinical suspicion of T2DM. Conversely, approximately $40 \%$ of diabetic patients were found to be of normal weight and as many as $30 \%$ of these demonstrated AN i.e. $12 \%$ of all diabetic patients were of normal weight yet manifested AN. AN in traditionally low-risk groups may be a valuable indicator of T2DM. However, in the absence of a control group in this study, we were unable to quantify this effect.

The interaction between BMI and ethnicity revealed interesting findings. Among obese diabetic patients, AN was most prevalent among East Indians. Among diabetic patients of normal weight however, Africans had a 1.7 times greater odds of demonstrating AN than East Indians of the same age, sex and waist circumference. Although the study was insufficiently powerful to show that this OR was different from one, this unexpected finding suggests that AN could be more prevalent among African than East Indian diabetic patients of normal weight, and this finding is worthy of further exploration in appropriately-powered studies.

AN can be rapidly assessed at the neck making it an extremely practical risk assessment tool. Examination for AN at other sites of the body can also marginally improve detection of T2DM. Among diabetic patients in this study, $52.7 \%$ had AN at the neck with or without $\mathrm{AN}$ at other sites, and a further $4.8 \%$ (approximately 1 in 20 diabetic patients) had AN only at other sites. Similar findings of neck involvement in $93 \%$ to $99 \%$ of AN was noted in the literature $[13,21]$. The low sensitivity of this further examination for $\mathrm{AN}$ at other sites, together with the additional time demands that it incurs, may render it impractical in routine practice. AN at other sites has also been less extensively described and quantified than AN at the neck and this may affect the validity of its routine assessment [13]. Potentially, the presence of AN at other sites may still provide useful evidence of T2DM risk in uncertain situations.

So far, we have discussed AN as a tool for improving the detection of undiagnosed T2DM. However, AN is also an important predictor of future T2DM. Stuart et al. described it as "a readily visible marker of endogenous hyperinsulinemia and thus, a marker for risk of developing non-insulin-dependent diabetes" [20]. Therefore, like other established risk factors for T2DM, the presence of AN is a valuable tool for recommendation of early lifestyle change for the prevention of T2DM 
and its complications, especially in a population where it is so readily manifest.

Apart from exploring $\mathrm{AN}$ as a valuable adjunct to T2DM screening, its link to other cardiovascular risk factors was explored. In this study, AN was found to have a demographic-adjusted association with each of obesity, hypertension and hypercholesterolemia. However, in our further multivariable analysis with all three variables (as well as demographic variables), only obesity remained associated with AN while the latter two did not. Consistent with this, a strong association between obesity, its accompanying insulin resistance, and AN is widely documented $[8,19]$, and these findings emphasize that the presence of AN is more closely aligned with obesity than other cardiovascular risk factors.

One limitation of this study was that it did not allow for formal quantification of improvement in sensitivity of T2DM risk assessment attributable to the addition of AN to the pool of current risk factors. Such an assessment would provide valuable evidence to support health policy decision making. The promising results presented here favour further research into quantifying the benefit of $\mathrm{AN}$ in preparation for formal policy recommendation.

Another important limitation was that the study was conducted in a population of diabetic patients only. Therefore, the specificity of AN as a marker of T2DM could not be assessed. Study findings suggest that AN is a prevalent risk factor that can support clinical decision making. However, lack of information on the specificity of AN limits our ability to draw conclusions on whether the presence of AN alone or in traditionally low-risk groups is enough on its own to warrant screening for T2DM. If AN were found to be relatively non-specific, then its stand-alone value would be limited. Importantly, however, AN also predicts future T2DM making any measure of specificity difficult to interpret: while low specificity may mean that fewer cases will truly have T2DM, detection of AN provides an opportunity for preventing or delaying future T2DM. Schwartz reported that "it now appears that most, if not all, obesity-related $\mathrm{AN}$, as well as syndromic $\mathrm{AN}$, is related to insulinresistant states" [8].

We also recognise that diabetic patients in our study were sampled only from tertiary hospitals and our findings may therefore be more representative of diabetic patients with more severe disease. Since AN is associated with more severe disease [15], our estimate of the prevalence of AN may be an over-estimation and should be extrapolated to the general population of diabetic patients with caution. Additionally, our inferences concerning the usefulness of $\mathrm{AN}$ in detecting undiagnosed T2DM, are based on the assumption that the distribution of risk factors for T2DM in alreadydiagnosed diabetic patients will be reflective of that seen in undiagnosed patients, and this assumption may not necessarily be true.

\section{Conclusions}

Among diabetic patients in Trinidad, AN is highly prevalent both overall and across age, sex and ethnic groups. The high prevalence of this established risk factor for T2DM, together with the simplicity and convenience of its assessment, support the implementation of $\mathrm{AN}$ as a valuable addition to T2DM risk assessment in Trinidad.

We recommend that AN should be proactively observed in routine clinical practice in Trinidadian and similar ethnic settings and that a finding of AN should increase clinical suspicion of T2DM. Further study into the specificity of AN is needed in order to understand its value as a marker in traditionally low-risk groups.

\section{Abbreviations}

AN: Acanthosis Nigricans; BMI: Body mass index; Cl: Confidence interval; CVA: Cerebrovascular accident; IQR: Interquartile range; LRT: Likelihood ratio test; med: Median; MI: Myocardial infarction; OR: Odds ratio; RBG: Random blood glucose; SD: Standard deviation; T2DM: Type 2 diabetes mellitus.

\section{Competing interests}

The authors declare that they have no competing interests.

\section{Authors' contributions}

ST and CM conceived the study. ST and CM designed and co-ordinated the study. SB and TS performed the statistical analyses. ST drafted the manuscript. SB, TS and ST revised the manuscript for important intellectual content. All authors read and approved the final manuscript.

\section{Acknowledgements}

The authors are grateful to the patients who participated in the study and would like to thank Dr. Anna Maria Affan and Dr. Joann Mohamed for their assistance with data collection.

Received: 20 March 2014 Accepted: 3 July 2014

Published: 9 July 2014

\section{References}

1. Central Statistical Office: Trinidad and Tobago 2011 Population and Housing Census Demographic report. Ministry of Health Republic of Trinidad and Tobago. 2011. [cited 2014 Jul 13]. Available from: http://cso.planning.gov.tt/ sites/default/files/content/images/census/TRINIDAD\%20AND\%20TOBAGO\% 202011\%20Demographic\%20Report.pdf.

2. Poon-King T, Henry M, Rampersad F: Prevalence and natural history of diabetes in Trinidad. Lancet 1968, 291(7535):155-160.

3. Miller GJ, Beckles GL, Maude GH, Carson DC, Alexis SD, Price SG, Byam NT: Ethnicity and other characteristics predictive of coronary heart disease in a developing community: principal results of the St James Survey, Trinidad. Int J Epidemiol 1989, 18(4):808-817.

4. Pan American Health Organisation, Ministry of Health Republic of Trinidad and Tobago: Trinidad and Tobago Chronic Non-Communicable Disease Risk Factor Survey (Pan American STEPS). 2012. [cited 2014 Feb 24]. Available from: http://www.health.gov.tt/downloads/Downloadltem.aspx?id=314.

5. Gulliford MC, Ariyanayagam-Baksh SM, Bickram L, Picou D, Mahabir D: Counting the cost of diabetic hospital admissions from a multi-ethnic population in Trinidad. Diabet Med 1995, 12(12):1077-1085.

6. American Diabetes Association: Type 2 diabetes in children and adolescents. Diabetes Care 2000, 23(3):381-389.

7. Kahn RC, Flier JS, Bar RS, Archer JA, Gorden P, Martin MM, Roth J: Insulin receptors, acanthosis nigricans, and insulin resistance. Lancet 1986, 327(8481):595-596.

8. Schwartz RA: Acanthosis nigricans. J Am Acad Dermatol 1994, 31(1):1-19. 
9. Miller JH, Rapini RP, Cruz PD Jr, Chan EF, Quirk CM, Elston DM: Acanthosis Nigricans. [cited 2014 Feb 24]. Available from: http://emedicine.medscape. com/article/1102488-overview\#a0199.

10. Grandhe N, Bhansali A, Dogra S, Kumar B: Acanthosis nigricans: relation with type 2 diabetes mellitus, anthropometric variables, and body mass in Indians. Postgrad Med J 2005, 81(958):541-544.

11. Ogbera A, Akinlade A, Ajose O, Awobusuyi J: Prevalence of acanthosis nigricans and its correlates in a cross-section of Nigerians with type 2 diabetes mellitus. Trop Doct 2009, 39(4):235-236.

12. World Health Organisation, International Diabetes Federation: Definition And Diagnosis Of Diabetes Mellitus And Intermediate Hyperglycemia. Geneva, Switzerland: 2006. [cited 2014 Feb 24]. Available from: http://whqlibdoc. who.int/publications/2006/9241594934_eng.pdf?ua=1.

13. Burke JP, Hale DE, Hazuda HP, Stern MP: A quantitative scale of acanthosis nigricans. Diabetes Care 1999, 22(10):1655-1659.

14. Cuzick J: A wilcoxon-type test for trend. Stat Med 1985, 4(1):87-90

15. Litonjua P, Piñero-Piloña A, Aviles-Santa L, Raskin P: Prevalence of acanthosis nigricans in newly-diagnosed type 2 diabetes. Endocr Pract 2004, 10(2):101-106.

16. Centers for Disease Control and Prevention: About BMI for Adults. [cited 2014 Jul 13]. Available from: http://www.cdc.gov/healthyweight/assessing/ bmi/adult_bmi/index.html?s_cid=tw_ob064.

17. World Health Organisation: Obesity: preventing and managing the global epidemic. Report of a WHO consultation. World Health Organ Tech Rep Ser 2000, 894:1-253.

18. Caribbean Health Research Council, Pan American Health Organisation: Managing Diabetes in Primary Care in the Caribbean. 2006. [cited 2014 Feb 24]. Available from: http:/www.chrc-caribbean.org/Portals/0/Downloads/ Publications/Clinical\%20Guidelines/Diabetes\%20Guidelines.pdf.

19. Sinha S, Schwartz RA: Juvenile acanthosis nigricans. J Am Acad Dermatol 2007, 57(3):502-508

20. Stuart CA, Smith MM, Gilkison CR, Shaheb S, Stahn RM: Acanthosis Nigricans among Native Americans: an indicator of high diabetes risk. Am J Public Health 1994, 84(11):1839-1842.

21. Stuart CA, Gilkison CR, Smith MM, Bosma AM, Keenan BS, Nagamani M: Acanthosis nigricans as a risk factor for non-insulin dependent diabetes mellitus. Clin Pediatr 1998, 37(2):73-79.

22. American Diabetes Association: Screening for type 2 diabetes. Diabetes Care 2004, 27:S11-S14.

23. Banerji MA, Faridi N, Atluri R, Chaiken RL, Lebovitz HE: Body composition, visceral fat, leptin, and insulin resistance in Asian Indian men. J Clin Endocrinol Metab 1999, 84(1):137-144.

24. Batson YA, Teelucksingh S, Maharaj R, Singh V, Balkaran S, Cockburn B: Screening for diabetes in schoolchildren in Trinidad, West Indies. Paediatr Int Child Health 2013, 33(1):37-41.

25. Burghen GA, Givens JR, Kitabchi AE: Correlation of hyperandrogenism with hyperinsulinism in polycystic ovarian disease. J Clin Endocrinol Metab 1980, 50(1):113-116.

26. Dunaif A: Insulin resistance and the polycystic ovary syndrome: mechanism and implications for pathogenesis. Endocr Rev 1997 18(6):774-800.

27. Hud JA, Cohen JB, Wagner JM, Cruz PD: Prevalence and significance of acanthosis nigricans in an adult obese population. Arch Dermatol 1992, 128(7):941-944.

\section{Submit your next manuscript to BioMed Central and take full advantage of:}

- Convenient online submission

- Thorough peer review

- No space constraints or color figure charges

- Immediate publication on acceptance

- Inclusion in PubMed, CAS, Scopus and Google Scholar

- Research which is freely available for redistribution

Submit your manuscript at www.biomedcentral.com/submit
Biomed Central 